\author{
Ali Shiri, School of Library and Information Studies, University of Alberta, Edmonton, \\ Alberta, Canada
}

\title{
CAIS PAPER: The MANY FACES OF MARCIA BATES'S CONTRIBUTIONS: SYSTEM DESIGN INFLUENCE AND CITATION IMPACT
}

Abstract: This paper provides a current and holistic perspective of the citations made to Marcia Bates's work using a variety of data and citation sources. Further, it will provide new insight into the ways in which Bates's scholarly work has influenced the design and development of Information Retrieval (IR) systems and search interfaces.

\section{Introduction}

Marcia Bates is one of the versatile and influential scholars in information science whose scholarly work has spanned the past five decades. Her work has been widely read, recognized, cited and used by numerous researchers from a broad array of disciplines. The rationale for writing this paper is two-fold. The first is that this author's research work and publications on the design and evaluation of thesaurus-enhanced search interfaces, and subject access and query expansion in digital libraries and IR systems have been influenced by Bates's work. This body of work includes such writings as a PhD thesis, numerous journal articles, conference papers and the book that the author published with ASIST in 2012, for which Bates wrote an endorsement. In addition, evidence of Bates's influence on the author's work can be more concretely found in Marcia Bates's remarks in her Oral History Interview with Michael Buckland in 2012, where she makes a reference to the author's work as following her ideas. The second reason for this research is that studies that have identified influential information scientists in the past two decades have mainly addressed Bates's research areas, expertise, domain knowledge and scholarly strength. However, there is little work on demonstrating and documenting the impact and influence of Bates's work on the actual design and implementation of IR systems, search user interfaces and digital libraries.

Therefore, this paper addresses two key objectives. The first objective is to provide a quantitative overview of the citations made to Bates's work as reflected in various digital libraries and citation databases in order to gain a holistic and current perspective of the scope of her authorship, influence and impact on information science. The second objective is to closely examine a select number of Bates's publications on the design of IR systems, search user interfaces and digital libraries, and to demonstrate and document examples of IR systems, search user interfaces and digital libraries that have been influenced by her research. This study focuses specifically on Bates's citation image makers; those authors who have cited her in various publications. 


\section{Literature Review}

Citation analysis, publication counts and bibliometric methods have been used to study influential information science scholars. Citation context and content analysis has also been employed to examine the motivations for and categories of citations in various subject areas and disciplines (Bornmann, and Daniel, 2008). Citation analysis and bibliometric techniques have been used to capture the intellectual image and identity of three information scientists (Cronin and Shaw, 2002) and also the intellectual impact and influences of one information scientist over the course of his varied career (Cronin and Shaw, 2007). White (2001) coined the term 'citation image-makers' to refer to all authors who cite a focal author and thereby create his or her citation image.

A number of studies have examined Marcia Bates's work and citations to her works. For instance, White and McCain (1998) list Bates as one of the top 21 prominent information scientists and a canonical author in the time period of 1972 - 1995. Based on an examination of the h-index factor, Cronin and Meho (2006) rank Marcia Bates number 3 in a list of 31 influential information science faculty from the United States. In a study of 12 information innovators, Cronin and Meho (2007) name Bates as one of the influential scholars of the discipline based on eight of her highly cited publications. Zhao and Strotmann (2008) named Bates one of the 15 active and influential authors in the period 1996-2005 and also considered her one of the major contributors to information science IS during that decade. In the 1996-2000 Bates's citation identity is mentioned as 'user studies (information seeking / searching behaviour, user-centered approach to IR, users and use)' 'scholarly communication and web' and in the period 2000-2005, her citation identity is considered to be in the area of 'Information retrieval interaction'.

In a bibliometric profiling of six distinguished information scientists, Sugimoto and Cronin (2012) examine 69 publications by Bates. They found that Bates has published in 17 venues, with more than $50 \%$ of her publications appearing in four journals: the Journal of the American Society for Information Science and Technology (JASIST), Information Processing \& Management (IP\&M), Online Review, and Reference Quarterly $(R Q)$, in descending order of number of publications. Most of Bates's highly cited works were solo publications. In an intellectual biography of 8 solo-authored publications by Bates, Hartel (2013) notes that Bates's achievement lies at the intersection "of information retrieval systems and user behavior. There, she has shed light on the vocabulary problem, interface design, search strategies and tactics, and the information seeking habits of different groups".

In a study of co-cited author retrieval and relevance theory, White (2015) notes that Bates and Belkin "singly and jointly, are the two names that suggest topical areas such as informationseeking behavior or interactive document retrieval". In a diagram for Bates, White (2015) suggests that Bates is closely cited with the information scientists Ray Fidel, Carol Fenichel, Tefko Saracevic, and Christine Borgman, predicting greater cognitive effects for anyone who reads their works jointly with hers. The prediction makes sense, because both she and they write in relatively qualitative ways about behavioral aspects of online information retrieval systems. 
This paper provides a current and more holistic perspective of citations to Bates's work using a variety of data and citation sources. Further, it will provide new insight into the ways in which Bates's scholarly work has influenced the design and development activities and projects.

\section{Methodology}

The methodology adopted in this study draws partially on the methodological framework reported by Cronin and Shaw (2007) in their study of Rob Kling in that it aims to study the intellectual impact of Bates's work as one information scientist as reflected in citations to her work. In addition, this study makes use of new methods and sources to enhance the analysis by drawing upon a wider range of information sources and text analysis methods.

Studies of citation analysis of LIS scholars have found that it is not safe to rely on one single source for citation analysis or for examining individual authors' contributions to the discipline and argue for the use of multiple sources, such as Scopus, Web of Science, and Google Scholar. (Meho and Yang, 2007). They note that although Scopus provides more comprehensive citation coverage of LIS and LIS-related literature than WoS for the period 1996-2005, the two databases complement rather than replace each other.

To address the first research objective, a comparative and quantitative overview of citations to Bates's work was conducted to provide a more holistic and inclusive perspective of Bates's work. To that end, a number of digital information sources were utilized, including Google Scholar, Scopus, Web of Science, Library and Information Science Source, and Library and Information Science Abstracts and ResearchGate. ResearchGate was included as a new academic social network that provides alternative metric information and also because Bates has a profile in ResearchGate. In addition, given the evidently incomplete list of publications in Bates's Google Scholar profile, it was decided to use Publish or Perish, an open source tool for retrieving and analyzing academic citations based on Google Scholar and Microsoft Academic Search. The software provides such metrics as the total number of papers and total number of citations, average citations per paper, citations per author, papers per author, and citations per year and Hirsch's h-index.

All the searches were conducted on December 20, 2016. Author search was conducted in LISA, Library and Information Science Source and Scopus. In Web of Science, an author search was conducted and two broad subject categories were selected to refine the search, including 'Information Science and Library Science' and 'Computer Science and Information Systems'. A keyword search was conducted in ResearchGate and Google Scholar.

To address the second research objective, 11 publications were selected from Bates's work based on the rationale that they should have a focus on the design of IR systems, search user interfaces, and digital libraries. A majority of these publications are among the highly cited works. To demonstrate and document examples of IR systems, search user interfaces and digital libraries that have been influenced by Bates's work, two methods will be used. First, individual citations to her selected works will be reviewed to identify if the citing work involves design, 
development and implementation of IR systems, search interfaces and digital libraries. Second, search statements were created to include exact phrasing of the selected titles along with the terms 'design, development, implementation ' and the key categories listed in Table 2, namely search interfaces and interaction, IR systems and subject access, and digital libraries. To achieve this for each of Bates's publications a Google Scholar search was confined to that publication to conduct focused searches within that citation. In addition, terms such as influence and impact were used during search. For examining each citing paper, the context and content of the reference was used as well as searches for Bates's name or in some examples specific keywords, for instance berry-picking model. Another search strategy used was to conduct searches for the names of technology companies within citations. These included web search engines and commercial databases vendors.

Google scholar, Scopus and Web of Science will be used to conduct searches on the above search statements. The results will provide specific examples and instances of design, development and implementation of IR systems and interfaces and digital libraries that have been influenced by Bates's work. Attention will also be paid to the institutional and corporate context of the citations.

\section{Findings}

\subsection{Number of citations}

Table 1 shows a comparative and quantitative overview of the publications by Marcia Bates as reflected in various digital libraries, citation databases and search engines. The key observation is the differences among these various sources in terms of coverage, citation counts and h-index factors. Another important and interesting finding is that over 3300 citations to Bates's work are in fact missing from her Google Scholar profile. A more curious observation is that the missing publications in Bates's Google Scholar profile are actually indexed in Google Scholar, but only retrievable using Publish and Perish. The links to Bates's publication in Publish and Perish retrieve these citations from Google Scholar.

\begin{tabular}{|l|l|l|l|}
\hline Search system & $\begin{array}{l}\text { No. of } \\
\text { Publications } \\
\text { indexed }\end{array}$ & Citations & h-index \\
\hline ResearchGate & 87 & 4257 & 30 \\
\hline Google Scholar & 43 & 4779 & 10 \\
\hline Scopus & 46 & 2369 & 19 \\
\hline $\begin{array}{l}\text { Library and Information } \\
\text { Science Abstracts (LISA) }\end{array}$ & 27 & -- & -- \\
\hline $\begin{array}{l}\text { Library and Information } \\
\text { Science Source }\end{array}$ & 67 & -- & -- \\
\hline Web of Science & 63 & 2082 & 21 \\
\hline Publish or Perish & 200 & 8141 & 38 \\
\hline
\end{tabular}

Table 1. A comparative and quantitative overview of Marcia Bates's publications and citations It should be noted that the search for Marcia Bates using Publish or Perish application retrieved publications by Marcia H Bates, whose expertise lies in the environmental and earth science area 
and her publications and citations had to be individually removed. Table 2 shows the publications selected to address the second research objective, namely Bates's publications that have a particular focus on IR system design, Search interfaces, and digital libraries.

\begin{tabular}{|c|c|c|c|c|c|}
\hline $\begin{array}{l}\text { Subject } \\
\text { areas }\end{array}$ & Publications & $\begin{array}{l}\text { Google } \\
\text { citations }\end{array}$ & $\begin{array}{l}\text { WoS } \\
\text { citations }\end{array}$ & $\begin{array}{l}\begin{array}{l}\text { Scopus } \\
\text { citations }\end{array}\end{array}$ & $\begin{array}{l}\text { Research } \\
\text { Gate }\end{array}$ \\
\hline \multirow{3}{*}{$\begin{array}{l}\text { search } \\
\text { interfaces } \\
\text { and } \\
\text { interaction }\end{array}$} & $\begin{array}{l}\text { Bates, M. J. (1989). The design of browsing and berry-picking } \\
\text { techniques for the online search interface. Online review, 13(5), } \\
407-424 \text {. }\end{array}$ & 1789 & 522 & 728 & 1367 \\
\hline & $\begin{array}{l}\text { Bates, M. J. (1990). Where should the person stop and the } \\
\text { information search interface start?. Information Processing \& } \\
\text { Management, 26(5), 575-591. }\end{array}$ & 451 & 152 & 183 & 280 \\
\hline & $\begin{array}{l}\text { Bates, M. J. (1990). The berry-picking search: User interface } \\
\text { design. User Interface Design. Addison-Wesley. }\end{array}$ & 30 & $\begin{array}{l}\text { Not } \\
\text { indexed }\end{array}$ & $\begin{array}{l}\text { Not } \\
\text { indexed }\end{array}$ & 22 \\
\hline \multirow{6}{*}{$\begin{array}{l}\text { IR systems } \\
\text { and } \\
\text { subject } \\
\text { access }\end{array}$} & $\begin{array}{l}\text { Bates, M. J. (1986). Subject access in online catalogs: A design } \\
\text { model. Journal of the American Society for Information Science, } \\
\text { 37(6), } 357 .\end{array}$ & 177 & 177 & 189 & 263 \\
\hline & $\begin{array}{l}\text { Bates, M. J. (1986). An exploratory paradigm for online } \\
\text { information retrieval. Intelligent Information Systems for the } \\
\text { Information Society. Amsterdam: North-Holland, 91-99. }\end{array}$ & 86 & $\begin{array}{l}\text { Not } \\
\text { indexed }\end{array}$ & $\begin{array}{l}\text { Not } \\
\text { indexed }\end{array}$ & 36 \\
\hline & $\begin{array}{l}\text { Bates, M. J. (1979). Information search tactics. Journal of the } \\
\text { American Society for information Science, 30(4), 205-214. }\end{array}$ & 629 & 229 & 268 & 338 \\
\hline & $\begin{array}{l}\text { Bates, M. J. (1977). System meets user: Problems in matching } \\
\text { subject search terms. Information Processing \& Management, } \\
\text { 13(6), 367-375. }\end{array}$ & 54 & 27 & 27 & 32 \\
\hline & $\begin{array}{l}\text { Bates, M. J. (1977). Factors affecting subject catalog search } \\
\text { success. Journal of the American Society for Information Science, } \\
\text { 28(3), 161-169. }\end{array}$ & 118 & 42 & 38 & 66 \\
\hline & $\begin{array}{l}\text { Bates, M.J. (1990) Design for a subject search interface and online } \\
\text { thesaurus for a very large record management database. In: Diane } \\
\text { Henderson (Ed.) Proceedings of the 53rd Annual Meeting of the } \\
\text { American Society for Information Science, Toronto, Ontario, } \\
\text { November 4-8 1990. Medford, NJ: Learned Information, pp.20-28. }\end{array}$ & 20 & 3 & $\begin{array}{l}\text { Not } \\
\text { indexed }\end{array}$ & $\begin{array}{l}\text { Not } \\
\text { indexed }\end{array}$ \\
\hline \multirow[t]{2}{*}{$\begin{array}{l}\text { Digital } \\
\text { libraries }\end{array}$} & $\begin{array}{l}\text { Bates, M. J. (1998). Indexing and access for digital libraries and } \\
\text { the Internet: Human, database, and domain factors. Journal of the } \\
\text { American Society for Information Science, 49(13), 1185-1205. }\end{array}$ & 261 & 86 & 108 & 189 \\
\hline & $\begin{array}{l}\text { Bates, M. J. (2002). The cascade of interactions in the digital } \\
\text { library interface. Information Processing \& Management, 38(3), } \\
\text { 381-400. }\end{array}$ & 117 & 29 & 39 & 80 \\
\hline
\end{tabular}

Table 2. Select list of Marcia Bates's publications, with a particular focus on IR system design, Search interfaces, and digital libraries 
The second objective of this study was to closely examine a select number of Bates's publications on the design of IR systems, search user interfaces and digital libraries, and to demonstrate and document examples of IR systems, search user interfaces and digital libraries that have been influenced by her research. For this part of the study the citation context and content of each publication was closely examined to establish whether the citing paper only makes a mention or in fact makes use of the ideas to design, develop, implement and test systems, interfaces and digital libraries. While initially 11 papers were selected to be examined in terms of citations, only 7 were short-listed as others were extended or expanded versions of initial ideas. The following articles were removed from the original list of 11 publications.

Bates, M. J. (1990). The berry-picking search: User interface design. User Interface Design. AddisonWesley.

Bates, M. J. (1986). An exploratory paradigm for online information retrieval. Intelligent Information Systems for the Information Society. Amsterdam: North-Holland, 91-99.

Bates, M. J. (1977). System meets user: Problems in matching subject search terms. Information Processing \& Management, 13(6), 367-375.

Bates, M. J. (1977). Factors affecting subject catalog search success. Journal of the American Society for Information Science, 28(3), 161-169.

Appendix 1 lists the selected 7 publications that were examined in this study along with the citing papers that used Bates's work as the basis for or as part of system design or interface design.

\section{Bates's Influence on Search User Interface Design: General Observations}

There were a number of key information retrieval and human computer interaction publications on search user interface design that have widely cited Bates's work. These publications (mainly books) discuss Bates's work from the perspective of search user interface design. For instance, Hearst (2009) makes various references to Bates's papers on the berry-picking model, information search tactics and the article "Where should the person stop and the information search interfaces start'. Wilson (2011) and Wilson and White (2009) use Bates's work to not only suggest user interface design guidelines, but also develop a holistic usability evaluation framework and methodology for search user interface design. In his book titled Interaction with Search Systems, White (2016) numerous references to Bates's work on berry-picking model and search tactics as they relate to interface design and search system functionality. Marchinonini and Komlodi (1998) note that BATES (1979a, 1979b) created a taxonomy of practical strategies and tactics that information seekers could use during search and, which also served as the basis for interface designs. Niu and Kelly (2014) note that Bates's classification of search tactics served as an important conceptual reference for the large number of empirical studies that followed and that recent studies of Web search have focused on Bates's search formulation and term tactics. In addition to information retrieval and HCI researchers, the information architecture community has widely benefited from Bates's berry-picking model. Rosenfield and Morville (2002) and Morville (2005) make extensive references to Bates's works to support their ideas of developing information architecture designs for various websites. 
The following provides a discussion of selected individual papers and the citing authors who have made specific references to Bates's work for designing and developing search systems, user interfaces and digital libraries.

\section{Article 1: The Design of Browsing and Berry-picking Techniques for the Online Search Interface (1989)}

Bates's berry-picking model has influenced the design and evaluation of a broad range of IR systems, OPACS, web search engines, websites, digital libraries, exploratory search systems, faceted search systems, browsing and visual search interfaces. Malik et al. (2006) report the design of an interactive IR system and note that the second major improvement of their interface was the addition of design elements based on the berry-picking model. Wilson (2009) developed a holistic usability evaluation method called Sii based on Bates's tactics and Belkins's Information Seeking Strategies (ISS) and evaluated a series of search systems and interfaces including: collaborative information search systems (Search Together by Microsoft), faceted search and browsing interfaces, digital libraries, and information architecture in a web company. Kajiyama and Satoh (2014) note that the berry-picking model has been used in many studies, and they make references to examples of expanded models and theories based on the berry-picking model and the developed retrieval systems.

\section{Article 2. Where Should the Person Stop and the Information Search Interface Start?(1990)}

This paper has been well cited in papers where there was a strong emphasis on design of search interfaces. Based on tactics, stratagems and strategies and the notions of strategic support and proactive support, Klas et al. (2004) developed a digital library system called Daffodil, whose architecture is structured according to these levels. Panasanato and Fortes (2007) present a system prototype based on orienteering to browse semantically-enhanced educational wiki pages. The system makes use of the levels of activity move, tactic, stratagem and strategy. Grigoreanu et al. (2009) from Microsoft research make use of the berry-picking model to improve Microsoft Excel, one of the most widely used spreadsheets and the most popular end-user programming environments. They make a reference to Bates's argument that search systems should be designed to make a good strategy easy to employ, by taking into account search behaviors which promote the strategic goals of searching for information. They further note that this advice also holds in designing debugging tools for end-user programming environments. A European Commission supported project developed a digital library called EZDL (Beckers et al., 2012, 2014), which makes extensive use of Bates's technical support including term suggestions for the search query or the extraction of frequent authors or terms from the result list. Suggestions of tactics and stratagems for furthering the search are shown to the user on request, based on casebased reasoning and previous feedback from other users about the usefulness of the suggestions. Morris and White (2011) in their US patent titled 'identification and use of web search expertise' make references to Bates's article. Also, Zhang, P., \& Koppaka (2010), both from Lexisnexis, A Division Of Reed Elsevier Inc., refer to this article in their US patent titled 'Citation network viewer and method'. 


\section{Article 3. Subject Access in Online Catalogs: A Design Model}

Based on Bates's design model, Belkin and Marchetti (1989) highlighted some design guidelines for intelligent creation of a user thesaurus, hierarchical organization of topics, display relative importance and frequency of a term in a database. Several researchers in the domain of expert systems and knowledge-based systems have made specific references to the design of subject access. This is due to the subject and semantic nature of Bates's design model and the importance of it as a mechanism to provide a variety of vocabulary for users to formulate search statements (Chen and Dhar, 1991; Alberico and Micco, 1990). Shiri et al. (2002) identified and documented a series of thesaurus-enhanced search interfaces that benefited from Bates's idea of thesaurus -enhanced search systems. White and Roth (2009) use several of Bates's publications including the berry-picking model and subject access in online catalogs to develop features for a new category of search systems called exploratory search systems, stressing the importance of moving beyond the query-response paradigm. In the final report for the Library of Conference Bicentennial Conference on Bibliographic Control for the New Millennium Taskforce Recommendation 2.3 on Research and Design Review: Improving User Access to Library Catalog and Portal Information, Bates (2003) also makes a number of recommendations for designing subject access, user access vocabulary and interfaces. The design of subject access in online catalogs has received extensive attention by researchers who studied the development of end-user thesauri, concept tools, super-thesauri, semantic networks, taxonomies, subject access tools, knowledge organization systems and online catalogs (Pollard, 1993; Shiri, 2012).

\section{Article 4. Information Search Tactics (1979)}

As part of developing an interface for a full text retrieval system at Digital's Customer Support Center called STARS, Anick et al (1989) made use of Bates's query reformulation strategies to facilitate query reformulation and experimentation, by making iterative adjustments to the query easy to perform. Smith et al. (1989) use the parallel tactic that Bates proposes in her paper to design an intermediary intelligent system where users' keywords could be interpreted and matched with additional terms for broadening the search. Brajnik et al. (1990) developed an expert system called Information Retrieval Natural Language Interface (IR-NLI) to support endusers in online searching and made use of search tactics to develop a user model for the prototype system. In developing an expert system for MICROARRAS, a full text search and retrieval engine, Gauch and Smith (1993), Bates's tactics provide the basic operations for our expert system. In particular, they make use of query reformulation strategies suggested by Bates. Brajnik et al. (2002) developed a prototype knowledge-based IR system called FIRE for coaching users based on search strategies and tactics suggested by Bates.

Morris and Teevan (2009) in their monograph on Collaborative Web Search highlight the importance of the search tactics suggested by Bates and note that such tactics as 'consult' and 'brainstorm' have inherently social nature and can be designed as components of collaborative web search systems. They also report that they found that brainstorming with others, particularly brainstorming alternative query keyword choices, was a common social interaction during information seeking tasks. In an evaluation of collaborative search interfaces, Wilson and Schraefel (2008) developed a framework based on Bates's search tactics and Belkin's Information Seeking Strategies and found that the framework could be just as easily applied to 
collaborative search interactions as individual seeking software. Using Bates's search tactics and Belkins's information seeking strategies, Wilson and Schraefel (2009) developed an analytical search interface inspector to evaluate the ways in which a search interface supports different information seeking behaviour. The tool can be used by the designers of search interfaces to quickly asses design ideas.

Janecek and $\mathrm{Pu}$ (2004) report the development of semantic fisheye views (SFEV) can be designed to effectively support opportunistic search, namely searching for more general or specific concepts throughout the search process. The proposed visual interface enables rapid, interactive exploration of the multiple contexts that is useful for different search strategies. Kriewel and Fuhr $(2007,2010)$ report the development and evaluation of an adaptive search suggestion system as part of the digital library platform. The system makes use of terminological suggestions, strategic suggestions, suggestions in regards to operators and advanced search suggestions. The system uses search tactics and strategies proposed by Bates. Thudt et al. (2015) propose guidelines for versatile search interfaces that are based on a modular approach to search. Based on Bates's search tactics, they developed what they called micro-strategies, such as querying, linking, and scanning. For digital libraries and book collections, they suggest visual overviews, different types of linking for exploration, search histories and exploration trails, playfulness and rich interaction, and fluidity through continuous navigation.

\section{Article 5. Design for a Subject Search Interface and Online Thesaurus for a Very Large Record Management Database (1990)}

Drawing upon Bates's work on 'Design for a Subject Search Interface and Online Thesaurus for a Very Large Records Management Database' and her information search tactic, Anick and Tipirneni (1999) developed a system called Paraphrase Search Assistant for the Altavista web search engine, which supports interactive query refinement through suggesting semantically related terms on the interface. In the design proposed by Bates (1990) of a subject search interface and online thesaurus, the online thesaurus is made in such a way that synonyms and term variations are clustered. The system was developed for the Los Angeles Department of Water and Power and the system search interface was enhanced using the Department's Thesaurus. This proposal allows for a larger entry vocabulary and the inclusion of partial matches between the user's term and those held in the thesaurus. The proposed design features allow the mapping of user-entered terms to those of the thesaurus and the use of the OR operator for combining all thesaurus terms selected by the user. The main feature of the interface is the display of alternative thesaurus terms without any hierarchical order or term type definition. Following the development of this interface, we observe a number of projects started in Europe, including the OKAPI project (Beaulieu, 1997), Hyperline (Agosti et al., 1992), HIBROWSE (Pollitt, 1994), and more recently in Canada (Shiri et al., 2011, 2013). Following these projects particularly in 1990s, we note that several database vendors began to create search user interfaces that incorporated thesauri to support semantically rich search experiences. These database vendors included Ovid, Ebsco, WilsonWeb, Cambridge Scientific Abstracts (CSA), Thomson Reuters Web of Knowledge, Engineering Village, and ProQuest. 


\section{Article 6. Indexing and Access for Digital Libraries and the Internet: Human, Database, and Domain Factors (1998)}

Smith et al. (2006) from Microsoft Research, introduced FacetMap, an interactive, query-driven visualization, generalizable to a wide range of metadata-rich data stores. FacetMap uses a visual metaphor for both input and output. The authors have designed this visual interface based on the idea of recognize versus recall proposed by Bates (1998). Sarkar (2014) developed a collaborative search system based on users, items, and keywords that make it easy for users to search for relevant items and relevant users (US Patent).

It should be noted that Bates's article titled 'Indexing and Access for Digital Libraries and the Internet (1998)' has received more attention by those who in developed, modified or enhanced thesauri, taxonomies and classification systems than designing systems or interfaces. This is due to the focus of the article on indexing and structuring content in digital information systems.

\section{Article 7. The cascade of interactions in the digital library interface}

A number of studies have cited this article and made use of it to develop conceptual designs for digital libraries (Sandusky, 2002; Butterworth 2006; Blandford et al., 2007), usability frameworks and methodologies (Wilson, 2011), and conceptual design of cultural heritage digital information systems (Stiller, 2012). Drawing on the cascade of interactions model, Beckers and Fuhr (2012) introduce the concept of user-oriented design of IR systems supporting different kinds of search tasks.

\section{Limitations}

It should be noted that numerous papers used these ideas to evaluate systems and interfaces, including websites, portals, digital libraries, OPACs, experimental IR systems, web search engines etc. Also, excluded from this paper are studies that have made use of Bates's model to develop new information search and seeking models. Bates's work has been used to categorize users' search strategies through analyzing web search logs. If we take a broad perspective of system design, this paper did not address the design and development of many controlled vocabularies and thesauri influenced by Bates's model of user thesaurus or Front-end System Mind (FSM). The focus of this paper was on citing papers that reported the design and development of systems and interfaces. In my book titled Powering Search (Shiri, 2012), which is heavily influenced by Bates's notion of vocabulary, subject access and search interface design, I have identified and critiqued more than 100 examples of search user interfaces that aim to achieve the same goal.

\section{Conclusion}

Our analysis of the selected publications by Bates demonstrates that these publications have influenced the conceptual and practical design, development, evaluation, improvement of a broad range of digital information systems, including online catalogues, expert systems, online 
databases, information retrieval systems, cross-lingual IR, interactive IR, web search engines, digital libraries, and cultural heritage websites; and collaborative information retrieval systems, including social question answering sites, query suggestion systems, exploratory search systems, faceted search systems, and enterprise and consumer search systems. While the focus of this study was not to examine the institutional affiliation of the citing authors to Bates's work, we gathered some data to provide a different perspective of the notion of influence and impact in the context of system design and development. Our brief analysis of the institutional affiliation of citing authors shows that researchers from Altavista (Anick, P. G., \& Tipirneni , 1999), Microsoft (Teevan, 2003; White and Horvitz, 2015), Yahoo! (Anick \& Tipirneni, 2003; Rose \& Levinson, 2004; Grigoreanu, 2012), Xerox from Xerox Palo Alto Research Center (Weyer, 1982; Rao et al., 1993; Pirolli and Card, 1995; Morville, 2005), Endeca (Kules et al. 2009), and the information architecture community (Morville and Rosenfield, 2002; Morville, 2005; Morville and Rosenfield, 2007) have made extensive use of and references to Bates's work.

\section{References}

Agosti, M., Gradenigo, G., \& Marchetti, P. G. (1992). A hypertext environment for interacting with large textual databases. Information Processing \& Management, 28(3), 371-387.

Alberico, R., \& Micco, M. (1990). Expert systems. Meckler.

Anick, P. G., Brennan, J. D., Flynn, R. A., Hanssen, D. R., Alvey, B., \& Robbins, J. M. (1989, December). A direct manipulation interface for boolean information retrieval via natural language query. In Proceedings of the 13th annual international ACM SIGIR conference on Research and Development Information Retrieval (pp. 135-150). ACM.

Anick, P. G., \& Tipirneni, S. (1999, August). The paraphrase search assistant: terminological feedback for iterative information seeking. In Proceedings of the 22nd annual international ACM SIGIR conference on Research and development in information retrieval (pp. 153-159). ACM.

Anick, P., \& Tipirneni, S. (2003). U.S. Patent No. 6,519,586. Washington, DC: U.S. Patent and Trademark Office.

Bates, M. J. (1998). Indexing and access for digital libraries and the Internet: Human, database, and domain factors. Journal of the American Society for Information Science, 49(13), 11851205. 
Bates, M. J. (2003, June). Task force recommendation 2.3 research and design review: improving user access to library catalog and portal information: final report (version 3). Library of Congress.

Beaulieu, M. (1997). Experiments on interfaces to support query expansion. Journal of Documentation, 53(1), 8-19.

Beckers, T., Dungs, S., Fuhr, N., Jordan, M., \& Kriewel, S. (2014). D3. 6: Final flexible user interface framework and documentation. Khresmoi project public deliverable.

Beckers, T., Dungs, S., Fuhr, N., Jordan, M., Kriewel, S., \& Tran, V. T. (2012, August). EZDL: An interactive search and evaluation system. In SIGIR 2012 workshop on open source information retrieval (pp. 9-16).

Beckers, T., \& Fuhr, N. (2012, April). Towards the systematic design of IR systems supporting complex search tasks. In Proceedings of the ECIR 2012 Workshop on Task-Based and Aggregated Search (TBAS2012) (p. 29).

Belkin, N. J., \& Marchetti, P. G. (1989, December). Determining the functionality features of an intelligent interface to an information retrieval system. In Proceedings of the 13th annual international ACM SIGIR conference on Research and Development in Information Retrieval (pp. 151-177). ACM.

Blandford, A., Keith, S., Butterworth, R., Fields, B., \& Furniss, D. (2007). Disrupting digital library development with scenario informed design. Interacting with Computers, 19(1), 70-82.

Bornmann, L., \& Daniel, H.D. (2008). What do citation counts measure? A review of studies on citing behavior. Journal of Documentation, 64(1) 45-80.

Brajnik, G., Guida, G., \& Tasso, C. (1990). User modeling in expert man-machine interfaces: A case study in intelligent information retrieval. IEEE Transactions on Systems, Man, and Cybernetics, 20(1), 166-185.

Brajnik, G., Mizzaro, S., Tasso, C., \& Venuti, F. (2002). Strategic help in user interfaces for information retrieval. Journal of the Association for Information Science and Technology, 53(5), 343-358.

Buckland, M. (2014) Marcia Bates Oral History Interview. Interview Michael Buckland. Retrieved January 5, 2017 from: http://infoscileaders.libsci.sc.edu/asis/wpcontent/uploads/2014/04/Bates-Transcript.pdf

Butterworth, R. (2006). Gathering user requirements when you do not know who the users are: a case study of digital library development. Technical Report IDC-TR-2006-002, Interaction Design Centre, School of Computing Science, Middlesex University. 
Chen, H., \& Dhar, V. (1991). Cognitive process as a basis for intelligent retrieval systems design. Information Processing \& Management, 27(5), 405-432.

Cronin, B., \& Meho, L. (2006). Using the h-index to rank influential information scientists. Journal of the American Society for Information Science and Technology, 57(9), 1275-1278.

Cronin, B., \& Meho, L. (2007). Timelines of creativity: a study of intellectual innovators in information science. Journal of the American Society for Information Science and Technology, 58(13), 1948-1959.

Cronin, B., \& Shaw, D. (2002). Identity-creators and image-makers: Using citation analysis and thick description to put authors in their place. Scientometrics, 54(1), 31-49.

Cronin, B., \& Shaw, D. (2007). Peers and spheres of influence: Situating Rob Kling. The Information Society, 23(4), 221-233.

Gauch, S., \& Smith, J. B. (1993). An expert system for automatic query reformation. Journal of the American Society for Information Science, 44(3), 124.

Grigoreanu, V. I., Burnett, M., \& Robertson, G. (2009). Design implications for end-user debugging tools: A strategy-based view. Technical Report. Accessed May 1, 2017 (http://ir.library.oregonstate.edu/xmlui/bitstream/handle/1957/12443/EUDToolsStrategiesApproach-Submitted.pdf?sequence=1)

Grigoreanu, V., Burnett, M., Wiedenbeck, S., Cao, J., Rector, K., \& Kwan, I. (2012). End-user debugging strategies: A sensemaking perspective. ACM Transactions on Computer-Human Interaction (TOCHI), 19(1), 5. (Microsoft)

Hartel, J. (2013). Castles and inverted castles: The work of Marcia J. Bates. Information Research: An International Electronic Journal, 18(3), n3.

Harzing, A. Publish or Perish: http://www.harzing.com/resources/publish-or-perish (accessed December 19, 2016).

Hearst, M. (2009). Search user interfaces. Cambridge University Press.

Janecek, P., \& Pu, P. (2004, November). Opportunistic search with semantic fisheye views. In International Conference on Web Information Systems Engineering (pp. 668-680). Springer Berlin Heidelberg.

Kajiyama, T., \& Satoh, S. I. (2014). An interaction model between human and system for intuitive graphical search interface. Knowledge and Information Systems, 39(1), 41-60.

Klas, C. P., Fuhr, N., \& Schaefer, A. (2004, September). Evaluating strategic support for information access in the DAFFODIL system. In International Conference on Theory and Practice of Digital Libraries (pp. 476-487). Springer Berlin Heidelberg. 
Kriewel, S., \& Fuhr, N. (2007, December). Adaptive search suggestions for digital libraries. In International Conference on Asian Digital Libraries (pp. 220-229). Springer Berlin Heidelberg.

Kriewel, S., \& Fuhr, N. (2010, March). Evaluation of an adaptive search suggestion system. In European Conference on Information Retrieval (pp. 544-555). Springer Berlin Heidelberg.

Kules, B., Tunkelang, D., \& White, R. W. (2009, December). HCIR 2009: the third international workshop on human-computer interaction and information retrieval. In ACM SIGIR Forum (Vol. 43, No. 2, pp. 83-87). ACM. ( Endeca).

Malik, S., Klas, C. P., Fuhr, N., Larsen, B., \& Tombros, A. (2006, September). Designing a user interface for interactive retrieval of structured documents-lessons learned from the INEX interactive track. In International Conference on Theory and Practice of Digital Libraries (pp. 291-302). Springer Berlin Heidelberg.

Meho, L. I., \& Yang, K. (2007). Impact of data sources on citation counts and rankings of LIS faculty: Web of Science versus Scopus and Google Scholar. Journal of the American Society for Information Science and Technology, 58(13), 2105-2125.

Morris, M. R., \& Teevan, J. (2009). Collaborative web search: Who, what, where, when, and why. Synthesis Lectures on Information Concepts, Retrieval, and Services, 1(1), 1-99.

Morris, D. S., \& White, R. W. (2011). U.S. Patent No. 7,996,400. Washington, DC: U.S. Patent and Trademark Office. (Microsoft)

Morville, P. (2005). Ambient findability: What we find changes who we become. "O'Reilly Media, Inc.".

Morville, P.; Rosenfield, L. (2007) Information Architecture for the World Wide Web. Sebastopol, CA: O'Reilly.

Niu, X., \& Kelly, D. (2014). The use of query suggestions during information search. Information Processing \& Management, 50(1), 218-234.

Pansanato, L. T., \& Fortes, R. P. (2007, June). System description: An orienteering strategy to browse semantically-enhanced educational wiki pages. In European Semantic Web Conference (pp. 809-818). Springer Berlin Heidelberg.

Pirolli, P., \& Card, S. (1995). Information foraging in information access environments. In Proceedings of the SIGCHI conference on human factors in computing systems (pp. 51-58). ACM Press/Addison-Wesley Publishing Co.

Pollard, R. (1993). A hypertext-based thesaurus as a subject browsing aid for bibliographic databases. Information Processing \& Management, 29(3), 345-357. 
Pollitt, A. S., Ellis, G. P., \& Smith, M. P. (1994). HIBROWSE for bibliographic databases. Journal of Information Science, 20(6), 413-426.

Rao, R., Russell, D. M., \& Mackinlay, J. D. (1993, December). System components for embedded information retrieval from multiple disparate information sources. In Proceedings of the 6th annual ACM symposium on User interface software and technology (pp. 23-33). ACM.

Rose, D. E., \& Levinson, D. (2004, May). Understanding user goals in web search. In Proceedings of the 13th international conference on World Wide Web (pp. 13-19). ACM.

Rosenfeld, L., \& Morville, P. (2002). Information architecture for the world wide web. "O'Reilly Media, Inc.".

Sandusky, R. J. (2002, July). Digital library attributes: framing usability research. In Proc. Workshop on Usability of Digital Libraries at JCDL (Vol. 2, pp. 35-38).

Sarkar, D. (2014). U.S. Patent No. 8,688,673. Washington, DC: U.S. Patent and Trademark Office. (US Patent).

Shiri, A. A., Revie, C., \& Chowdhury, G. (2002). Thesaurus-enhanced search interfaces. Journal of Information Science, 28(2), 111-122.

Shiri, A.; Ruecker, S.; Bouchard, M.; Doll, L.; Fiorentino, C. (2013) User Evaluation of Searching and T-Saurus: Multilingual Thesaurus-Enhanced Visual Interfaces for Digital Libraries. Canadian Journal of Information and Library Science, 37(2), pp. 137-160.

Shiri, A., Ruecker, S., Doll, L. Bouchard, M. \& Fiorentino, C. (2011). An Evaluation of Thesaurus-enhanced Visual Interfaces for Multilingual Digital Libraries. Proceedings of the International Conference on Theory and Practice of Digital Libraries, edited by Gradmann, S. et al. (Eds.), Lecture Notes in Computer Science (LNCS) 6966, Springer-Verlag, Berlin, pp. 236243.

Shiri, A. (2012). Powering Search: The Role of Thesauri in New Information Environments. (ASIS\&T Monograph Series) Medford, NJ: Information Today Inc.

Smith, G., Czerwinski, M., Meyers, B. R., Robertson, G., \& Tan, D. S. (2006). FacetMap: A scalable search and browse visualization. IEEE Transactions on visualization and computer graphics, 12(5).

Smith, P. J., Shute, S. J., Galdes, B., \& Chignell, M. H. (1989). Knowledge-based search tactics for an intelligent intermediary system. ACM Transactions on Information Systems (TOIS), 7(3), 246-270. 
Stiller, J. (2012). A framework for classifying interactions in cultural heritage information systems. International Journal of Heritage in the Digital Era, Volume 1, Supplement 1, Pages 141-146.

Sugimoto, C. R., \& Cronin, B. (2012). Biobibliometric profiling: An examination of multifaceted approaches to scholarship. Journal of the American Society for Information Science and Technology, 63(3), 450-468.

Teevan, J. (2003). The Re-Search Engine: Helping People Return to Information in Dynamic Information Environments (Doctoral dissertation, Ph. D. Thesis Proposal, Massachusetts Institute of Technology).

Thudt, A., Hinrichs, U., \& Carpendale, S. (2015, June). A Modular approach to promote creativity and inspiration in search. In Proceedings of the 2015 ACM SIGCHI Conference on Creativity and Cognition (pp. 245-254). ACM.

Weyer, S. A. (1982). The design of a dynamic book for information search. International Journal of Man-Machine Studies, 17(1), 87-107.

White, H. D. (2001). Author-centered bibliometrics through CAMEOs: Characterizations automatically made and edited online. Scientometrics, 51(3), 607-637.

White, H. D. (2015). Co-cited author retrieval and relevance theory: examples from the humanities. Scientometrics, 102(3), 2275-2299.

White, H. D., \& McCain, K. W. (1998). Visualizing a discipline: An author co-citation analysis of information science, 1972-1995. Journal of the American Society for Information Science, 49(4), 327-355.

White, R. W. (2016). Interactions with search systems. Cambridge University Press.

White, R. W., \& Horvitz, E. (2015). Belief dynamics and biases in Web search. ACM Transactions on Information Systems (TOIS), 33(4), 18.

White, R. W., \& Roth, R. A. (2009). Exploratory search: Beyond the query-response paradigm. Synthesis Lectures on Information Concepts, Retrieval, and Services, 1(1), 1-98.

Wilson, M. L. (2009). An analytical inspection framework for evaluating the search tactics and user profiles supported by information seeking interfaces (Doctoral dissertation, University of Southampton).

Wilson, M. L. (2011). Search user interface design. Synthesis lectures on information concepts, retrieval, and services, 3(3), 1-143. 
Wilson, M. L., \& Schraefel, M. C. (2008). Evaluating collaborative search interfaces with information seeking theory. Workshop on Collaborative Information Retrieval, Pittsburgh, PA.

Wilson, Max L. \& Schraefel, M. C. (2009) Sii: the lightweight analytical search interface inspector. At JCDL09 Workshop: Lightweight User-Friendly Evaluation Knowledge for Digital Librarians, United States.

Wilson, M. L., \& White, R. W. (2009). Evaluating advanced search interfaces using established information seeking models. Journal of the American Society for Information Science and Technology, 60(7), 1407-1422.

Zhang, P., \& Koppaka, L. (2010). U.S. Patent No. 7,735,010. Washington, DC: U.S. Patent and Trademark Office.

Zhao, D., \& Strotmann, A. (2008). Evolution of research activities and intellectual influences in information science 1996-2005: Introducing author bibliographic coupling analysis. Journal of the American Society for Information Science and Technology, 59(13), 2070-2086. 


\section{Appendix 1. Selected Publications by Marcia Bates along with Influenced Authors}

\begin{tabular}{|c|c|c|}
\hline $\begin{array}{l}\text { Subject } \\
\text { areas }\end{array}$ & Publications & Influenced authors \\
\hline $\begin{array}{l}\text { search } \\
\text { interfaces } \\
\text { and } \\
\text { interaction }\end{array}$ & $\begin{array}{l}\text { 1. Bates, M. J. (1989). The design of } \\
\text { browsing and berry-picking techniques } \\
\text { for the online search interface. Online } \\
\text { review, 13(5), 407-424. }\end{array}$ & 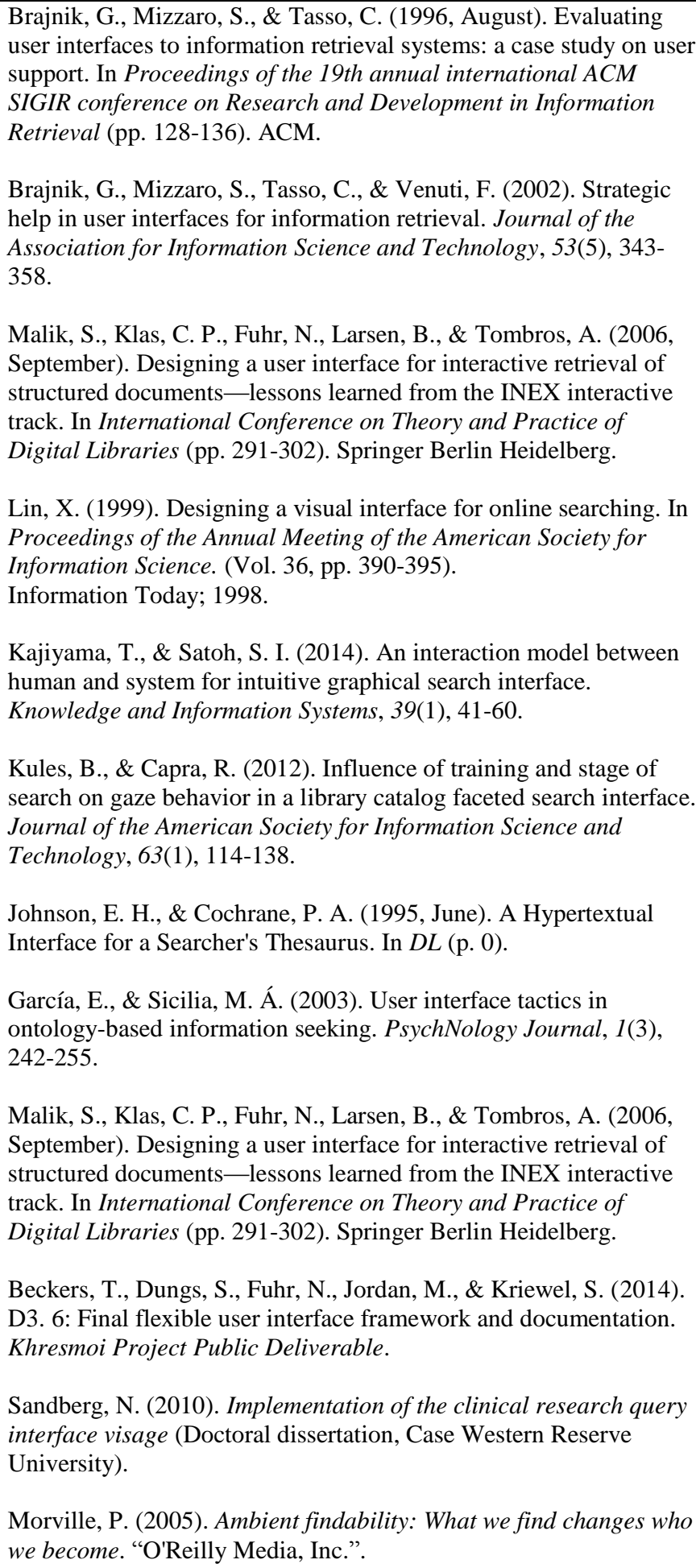 \\
\hline
\end{tabular}




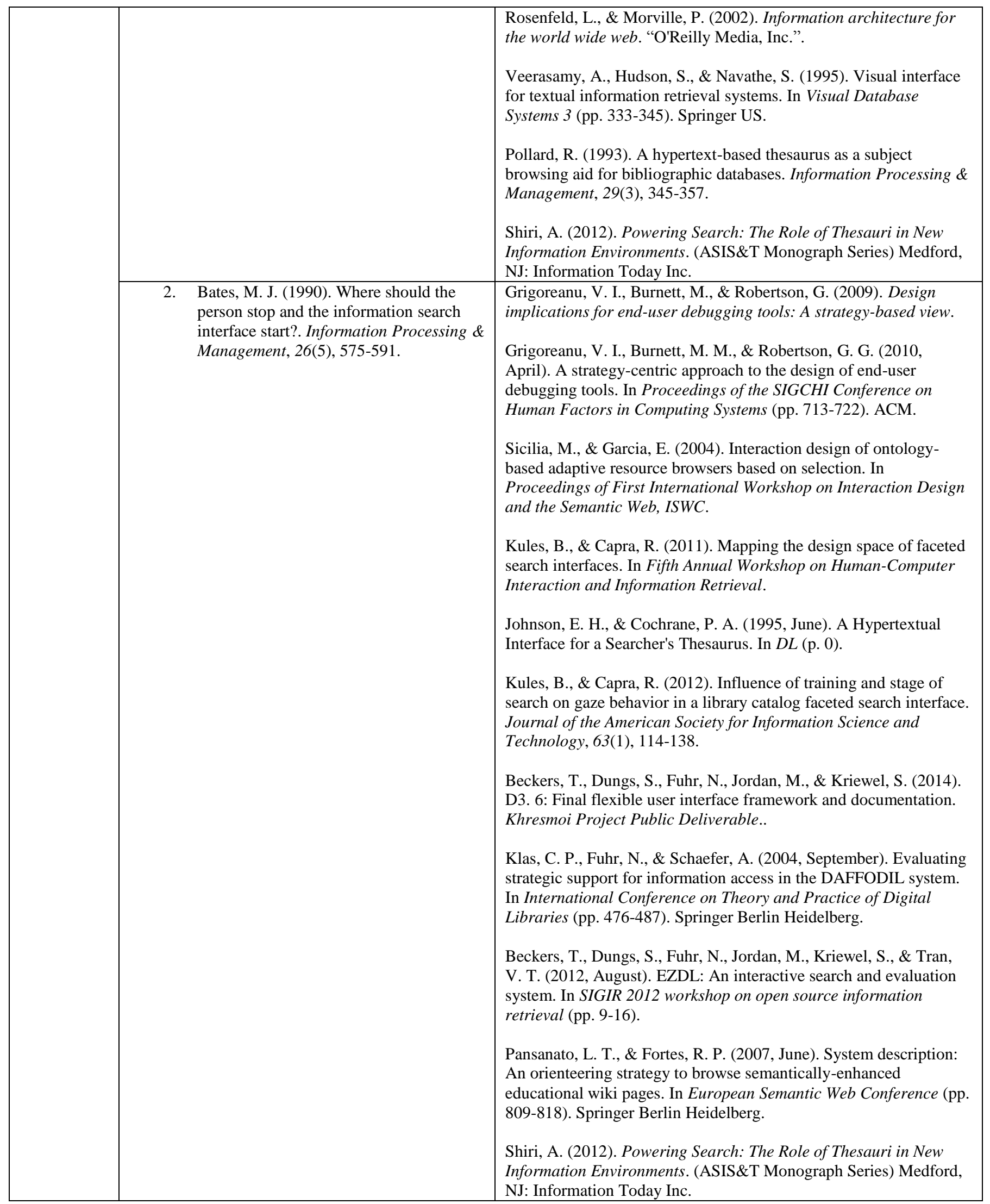




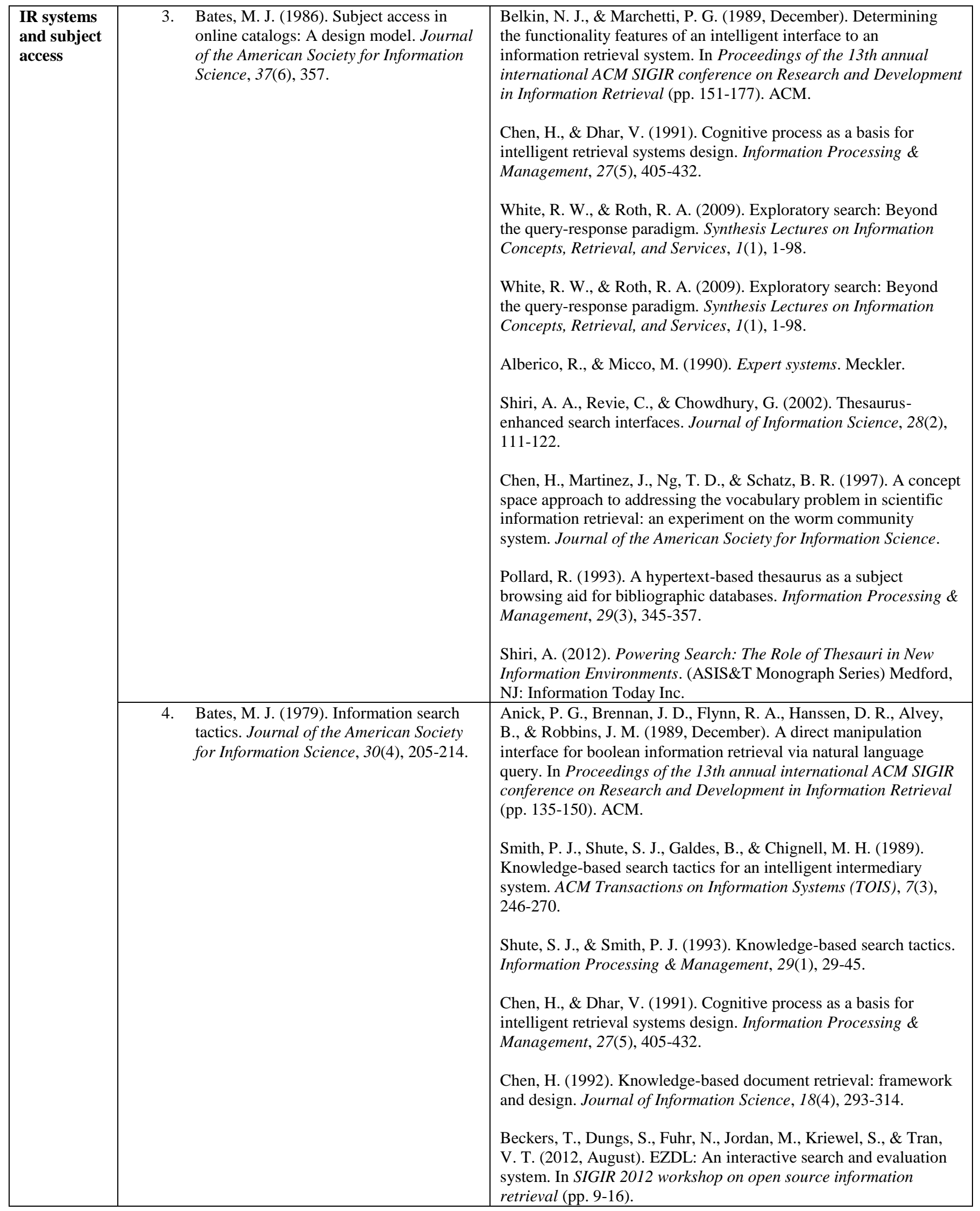


Morris, M. R., \& Teevan, J. (2009). Collaborative web search: Who, what, where, when, and why. Synthesis Lectures on Information Concepts, Retrieval, and Services, 1(1), 1-99.

Wilson, M. L., \& Schraefel, M. C. (2008).Evaluating Collaborative Search Interfaces with Information Seeking Theory. Workshop on Collaborative Information Retrieval, Pittsburgh, PA.

Brajnik, G., Mizzaro, S., Tasso, C., \& Venuti, F. (2002). Strategic help in user interfaces for information retrieval. Journal of the Association for Information Science and Technology, 53(5), 343358.

Kriewel, S., \& Fuhr, N. (2007, December). Adaptive search suggestions for digital libraries. In International Conference on Asian Digital Libraries (pp. 220-229). Springer Berlin Heidelberg.

Kriewel, S., \& Fuhr, N. (2010, March). Evaluation of an adaptive search suggestion system. In European Conference on Information Retrieval (pp. 544-555). Springer Berlin Heidelberg.

Janecek, P., \& Pu, P. (2004, November). Opportunistic search with semantic fisheye views. In International Conference on Web Information Systems Engineering (pp. 668-680). Springer Berlin Heidelberg.

Wilson, Max L. and Schraefel, M.C. (2009) Sii: the lightweight analytical search interface inspector At JCDL09 Workshop: Lightweight User-Friendly Evaluation Knowledge for Digital Librarians, United States.

Thudt, A., Hinrichs, U., \& Carpendale, S. (2015, June). A Modular Approach to Promote Creativity and Inspiration in Search. In Proceedings of the 2015 ACM SIGCHI Conference on Creativity and Cognition (pp. 245-254). ACM.

Tacke, A., \& Kriewel, S. (2014). Strategic search support on macro and micro level. Datenbank-Spektrum, 14(1), 19-28.

Beckers, T., Dungs, S., Fuhr, N., Jordan, M., Kontokotsios, G., Kriewel, S., \& Salampasis, M. (2014). EZDL: An Interactive IR Framework, Search Tool, and Evaluation System. In Professional Search in the Modern World (pp. 118-146). Springer International Publishing.

Beckers, T., Dungs, S., Fuhr, N., Jordan, M., \& Kriewel, S. (2014). D3. 6: Final flexible user interface framework and documentation. Khresmoi Project Public Deliverable.

Anick, P. G., \& Tipirneni, S. (1999, August). The paraphrase search assistant: terminological feedback for iterative information seeking. In Proceedings of the 22nd annual international ACM SIGIR conference on Research and Development in Information Retrieval (pp. 153-159). ACM.

Shiri, A. (2012). Powering Search: The Role of Thesauri in New Information Environments. (ASIS\&T Monograph Series) Medford, NJ: Information Today Inc. 


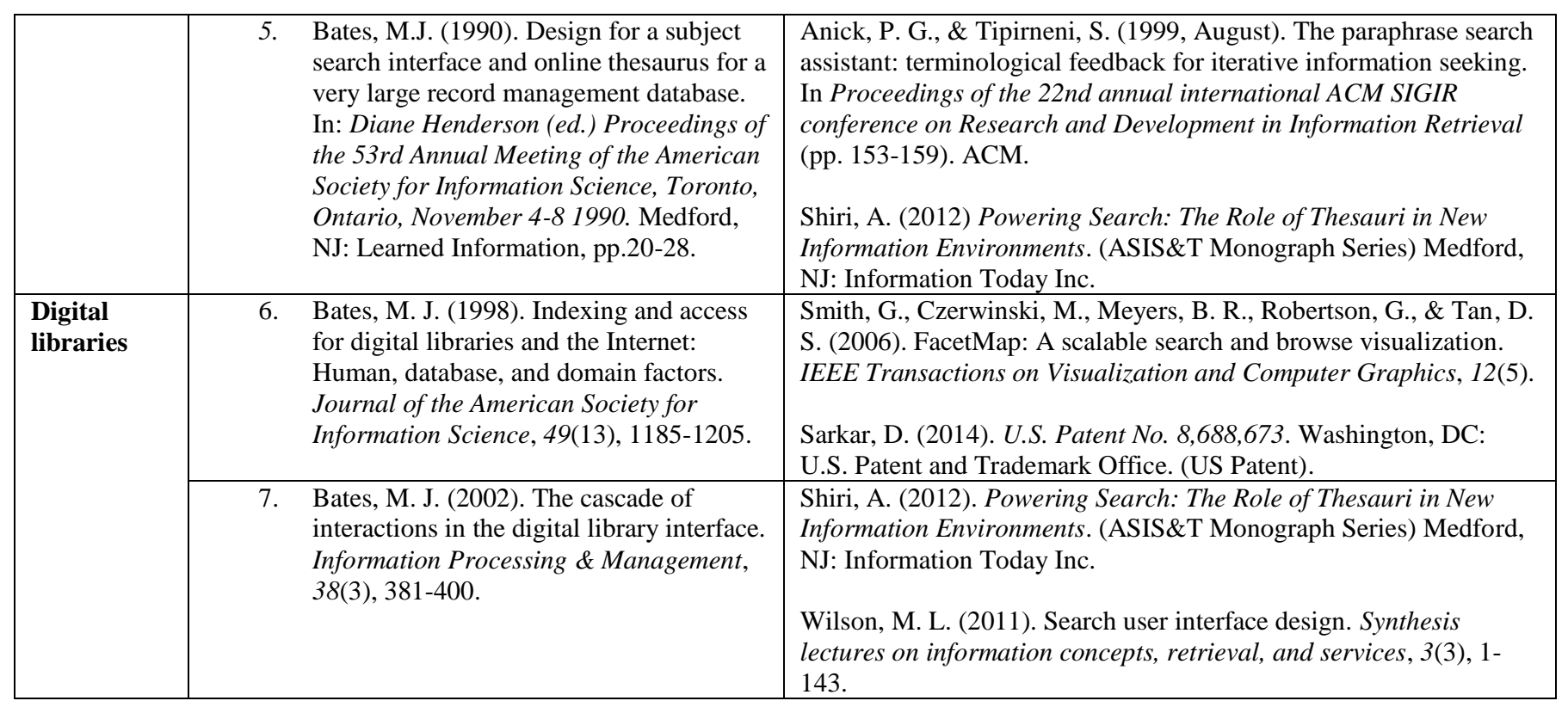

